\title{
RANCANG BANGUN 7-BAND GRAPHIC EQUALIZER SEBAGAI PENUNJANG PRAKTIKUM DASAR SISTEM KOMUNIKASI
}

\author{
Eko Supriyanto ${ }^{1}$, Aestatica Ratri ${ }^{2}$ \\ ${ }^{1}$ Laboratorium Pendidikan Teknik Telekomunikasi, Departemen Teknik Elektro,Politeknik \\ Elektronika Negeri Surabaya.Email: eko@staff.pens.ac.id \\ ${ }^{2}$ Laboratorium Pendidikan Teknik Telekomunikasi, Departemen Teknik Elektro,Politeknik \\ Elektronika Negeri Surabaya. email: ratri@staff.pens.ac.id
}

Submisi : 10 Oktober 2018; Penerimaan : 20 Februari 2019

\begin{abstract}
ABSTRAK
Rangkaian Filter merupakan salah satu rangkaian yang sangat penting baik dibidang audio maupun telekomunikasi. Oleh karena itu pengetahuan tentang rangkian filter ini perlu diajarkan kepada mahasiswa pada saat praktikum. Baik itu dari jenis filter, cara merancang hingga bagaimana cara mengukur dan menggambarkan karakteristik dari filter itu sendiri. Pada penelitian ini, dikenalkan tentang rangkaian ekualiser. Yang merupakan pengembangan dari rangkaian filter dasar yang telah dikenalkan sebelumnya kepada mahasiswa. Metode yang digunakan dalam penelitian ini adalah mengamati output dari rangkaian ekualiser, kemudian memplot hasil pengukurannya dalam bentuk grafik dengan skala semilog. Dan dari sini nantinya mahasiswa diharapkan bisa menganalisa output dari rangkaian ekualiser tersebut sekaligus bisa memahami salah satu bentuk modifikasi dari sebuah rangkaian filter dasar. Selanjutnya diharapkan mahasiswa bisa mengaplikasikan pengembangan rangkaian filter ini dalam sebuah kegiatan diluar praktikum.
\end{abstract}

Kata kunci : Rangkaian Filter; Ekualiser; Grafik Semilog; Karakteristik Filter.

\section{PENDAHULUAN}

\subsection{Latar Belakang}

Laboratorium bagi sebuah institusi pendidikan tinggi, khususnya politeknik, merupakan suatu hal yang sangat penting. Karena sistem pendidikan di politeknik mempunyai jam pelajaran praktikum yang sangat besar. Dan pemanfaatan fasilitas laboratorium begitu dibutuhkan.

Selain fisik dari laboratorium itu sendiri, yang tak kalah penting adalah peralatan-peralatan atau instrumentasi dan modul-modul praktikum yang ada didalam laboratorium tersebut. Peralatan atau instrumentasi laboratorium haruslah senantiasa siap untuk digunakan, baik untuk praktikum maupun untuk penelitian. Siap untuk digunakan disini berarti peralatan tersebut harus senantiasa terjaga kondisinya, tidak rusak atau hilang dan yang paling penting adalah peralatan tersebut dalam kondisi terkalibrasi dan sesuai dengan penggunaannya. Sedangkan modul untuk praktikum harus pula disesuaikan dengan kebutuhan dan perkembangan pengetahuan. Senantiasa ditingkatkan kualitasnya.

Salah satu modul praktikum yang ada di laboratorium dasar telekomunikasi adalah Active Filter. Modul ini berfungsi sebagai pembelajaran kepada mahasiswa tentang prinsip-prinsip dari rangkaian filter. Namun hanya sebatas Low Pass Filter dan High Pass Filter. Namun demikian bisa juga dikembangkan menjadi rangkaian Band Pass Filter dan Band Reject Filter.

Dengan bantuan modul tersebut mahasiswa bisa mengenal setidaknya empat jenis filter. Di dalam penelitian ini 
akan dibuat sebuah modul praktikum yang merupakan pengembangan dari rangkaian-rangkaian filter tersebut. Yaitu rangkaian ekualiser. Yang merupakan kombinasi dari beberapa rangkaian Band Pass Filter. Dan pada akhirnya diharapkan mahasiswa selain memahami beberapa rangkaian filter, juga mengetahui salah satu dari pengembangan rangkaian filter itu sendiri.

\subsection{Permasalahan yang Akan Diteliti}

Pada penilitian ini yang akan dilakukan adalah pengukuran karakteristik output rangkaian 7- Band Graphic Equalizer.

\subsection{Temuan yang Ditargetkan}

Diharapkan dengan melakukan penelitian ini, hasil yang didapatkan bisa diajarkan kepada mahasiswa sehingga mahasiswa bisa mengetahui rangkaian pengembangan dari beberapa filter yang telah dipelajari..

\subsection{Evaluasi dibidang Pengelolaan Laboratorium}

Sedangkan tujuan lain dari penelitian ini adalah nantinya bisa diterapkan sebagai salah satu judul dari mata kuliah Praktikum Dasar Sistem Komunikasi untuk mengamati karakteristik output sebuah ekualiser.

\section{TINJAUAN PUSTAKA}

\subsection{Definisi Filter dan Ekualiser}

Filter adalah sebuah komponen atau sebuah rangkaian yang berfungsi bebagai penapis atau peredam dari range frekuensi tertentu dan melewatkan range frekuensi tertentu. Range frekuensi yang diredam oleh rangkaian filter biasanya disebut Stop Band sedangkan range frekuensi yang dilewatkanoleh rangkaian filter tersebut disebut Pass Band. Karakteristik sebuah filter ditunjukkan pada gambar 1 dibawah ini.

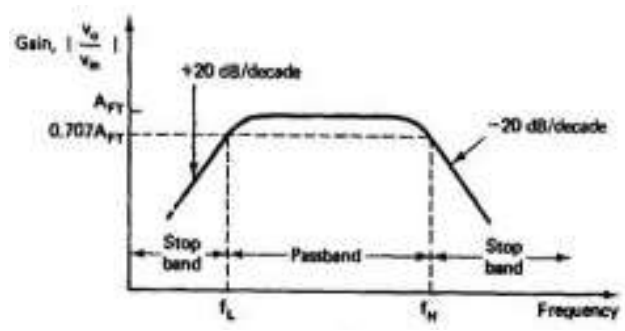

Gambar 1. Respon Frekuensi dari sebuah filter

Untuk filter yang melewatkan range frekuensi dibawah frekuensi cutoff nya disebut Low Pass Filter dan filter yang melewatkan range frekuensi diats frekuensi cuttoffnya disebut High Pass Filter. Sedangkan filter yang melewatkan range frekuensi diantara dua frekuensi cutoffnya disebut Band Pass Filter.

Filter pasif adalah sebuah rangkaian filter yang tidak mempunyai komponen penguat, dan hanya berisi komponen pasif saja. Sedangkan filter aktif didalamnya terdapat komponen penguat, misalnya sebuah transistor atau sebuah Op-Amp. Dan ekualiser adalah sekumpulan filter, biasanya kumpulan dari Band Pass Filter, yang berfungsi untuk melewatkan frekuensifrekuensi tertentu dengan jumlah rangkaian Band Pass tertentu pula. Pada penelitian kali ini akan dirancang sebuah rangkaian ekualiser 3 kanal.

\subsection{Pass band}

Pass Band adalah sebuah band atau renge frekuensi tertentu dari rangkaian filter dihitung dari penurunan 3 desibel dari nilai maksimum penguatan filter tersebut hingga nilai maksimum dari penguatan filetr tersebut.

\subsection{Stop Band}

Stop band adalah nilai range frekuensi pada kurfa karakteristik filter 
dibawah 3 desibel penguatan maksimumnya.

\subsection{Cutoff Frekuensi}

Cutoff Frekuensi adalah nilai frekuensi tepat pada saat nilai penguatan dari filter tersebut bibawah 3 desibel dari penguatan maksimalnya.

\subsection{Bandwidth}

Bandwidth adalah lebar frekuensi antara dua nilai frekuensi cutoff pada sebuah filter Band Pass.

\subsection{Rangkaian Ekualiser}

Rangkaian sebuah ekualiser merupakan gabungan dari beberapa rangkaian Band Pass Filter. Salah satu contohnya seperti terlihat pada gambar 2 berikut ini.

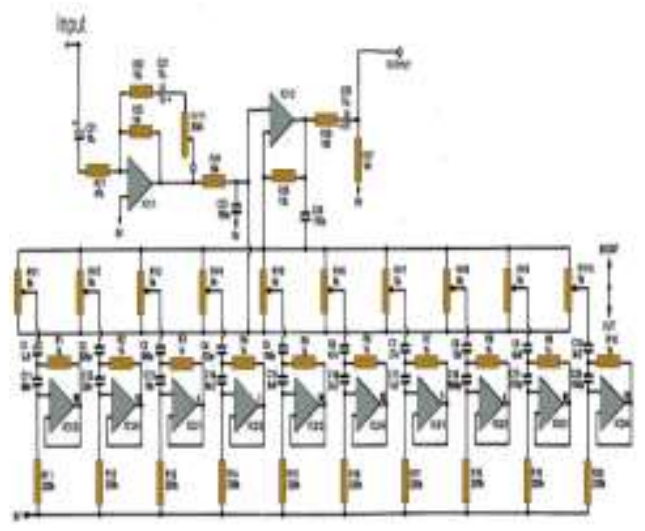

(a)

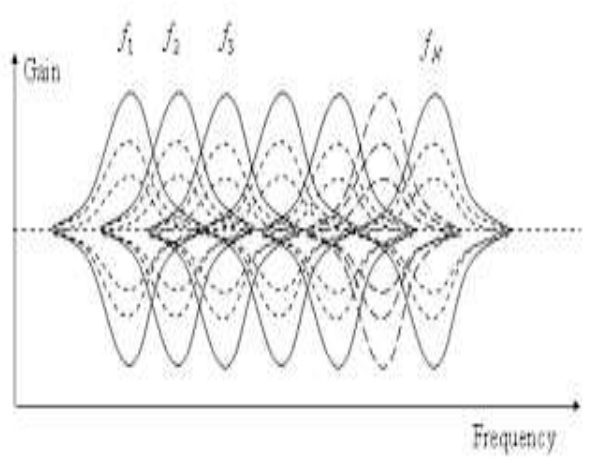

(b)
Gambar 2. Contoh rangkaian Ekualiser

(a) dan respon frekuensinya (b)

\section{METODE PENELITIAN}

\subsection{Metodologi}

Untuk pengukuran output dari suatu rangkaian ekualiser, diperlukan peralatan sebagai berikut, Function Generator sebagai pembangkit sinyal, rangkaian ekualiser serta sebuah osiloskop untuk menampilkan gelombang output sekaligus untuk mengukr tegangan output dari ekualiser.

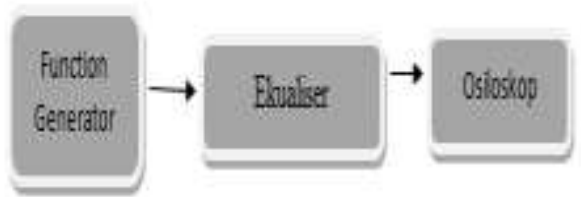

Gambar 3. Skema Pengukuran

Setelah semua peralatan terpasang, kita bisa memulai proses pengukuran dan pengamatan keluaran dari rangkaian ekualiser.

\subsection{Pengamatan dan Analisa}

Kita set output dari function generator dengan nilai tegangan konstan dan kita ubah-ubah nilai frekuensinya pada range frekunsi audio. Output dari function generator kita masukkan ke input rangkaian ekualiser dan output dari rangkaian ekualiser dihubungkan ke osiloskop untuk mengamati gelombang outputnya dan menghitung nilai tegangan outputnya. Setelah semua nilai frekuensi terukur, maka kita plot hasil dari tabel pengukuran ke dalam grafik semilog.

Pada tabel 1 bisa kita amati langkah-langkah dalam mengukur karakteristik dari Ekualiser. Untuk Position, kita isi posisi dari masingmasing potensio kanal ekualiser. Sedangkan Vin merupakan tegangan input yang kita umpankan pada rangkaian ekualiser. 
Tabel 1. Contoh Tabel Pengukuran karakteristik Ekualiser Position :

Vin :

\begin{tabular}{|c|c|c|c|c|}
\hline No. & $\begin{array}{c}\text { Freq } \\
(\mathrm{Hz})\end{array}$ & $\begin{array}{c}\text { Vo } \\
(\mathrm{V})\end{array}$ & Vo/Vi & $\mathrm{dB}$ \\
\hline 1 & 10 & & & \\
\hline 2 & 20 & & & \\
\hline 3 & 30 & & & \\
\hline 4 & 50 & & & \\
\hline 5 & 100 & & & \\
\hline 6 & 200 & & & \\
\hline 7 & 300 & & & \\
\hline 8 & 500 & & & \\
\hline 9 & $1 \mathrm{k}$ & & & \\
\hline 10 & $2 \mathrm{k}$ & & & \\
\hline 11 & $3 \mathrm{k}$ & & & \\
\hline 12 & $5 \mathrm{k}$ & & & \\
\hline 13 & $10 \mathrm{k}$ & & & \\
\hline 14 & $20 \mathrm{k}$ & & & \\
\hline
\end{tabular}

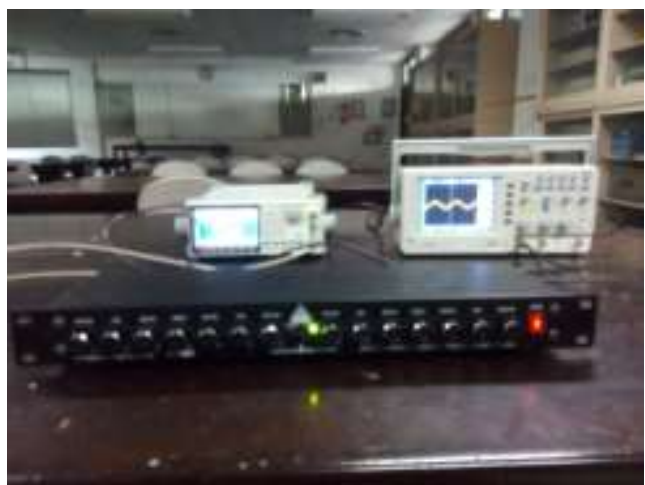

Gambar 4. Pengukuran Karakteristik Ekualiser

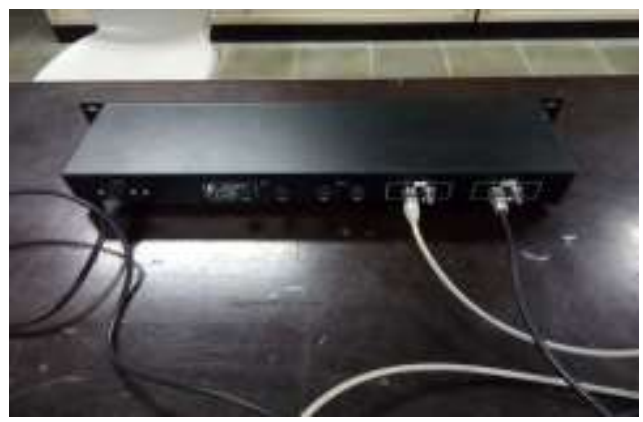

Gambar 5. Pengkabelan Pengukuran Karakteristik Ekualiser
Setelah semua instrumentasi dan modul terhubung, atur frekuensi dari Function Generator sesuai dengan tabel 1. Dan ukur berapa tegangan output dari ekualiser dengan menggunakan osiloskop. Hitung perbandingan antara tegangan output dengan tegangan input pada kolom $\mathrm{Vo} / \mathrm{Vi}$ serta kita rubah besarannya dalam satuan decibel dengan menggunakan rumus :

$\mathrm{dB}=20 \log \left(\frac{\mathrm{Vo}}{\mathrm{Vi}}\right)$.

Terakhir, kita plot data antara frekuensi dengan decibel dalam skala semilog untuk mendapatkan karakteristik dari ekualiser tersebut.

Tabel 2. Skema Pengukuran

\begin{tabular}{|c|c|c|c|c|c|c|c|}
\hline a) (GH & H1 & $\mathrm{Ol}$ & $\mathrm{CH}_{5}$ & F & $\mathrm{OH} 5$ & OHF & $\mathrm{OH}$ \\
\hline 1 & F & $\mathrm{f}$ & F & c & F & $F$ & 5 \\
\hline l & 8 & 8 & b & & 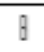 & 8 & ] \\
\hline \} & c & c & [ & & 6 & c & c \\
\hline 4 & 8 & $\mathrm{f}$ & $\mathrm{F}$ & & $\mathrm{f}$ & $\mathrm{f}$ & f \\
\hline 5 & l & $\mathrm{f}$ & $\mathrm{F}$ & & 1 & $\mathrm{~F}$ & $\mathrm{r}$ \\
\hline 6 & $\mathrm{~F}$ & 8 & F & & f & $\mathrm{F}$ & F \\
\hline 7 & $\mathrm{~F}$ & c & $r$ & 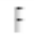 & $\mathrm{F}$ & $\mathrm{F}$ & $\mathrm{f}$ \\
\hline 1 & F & $\mathrm{f}$ & B & & $\mathrm{f}$ & $\mathrm{F}$ & F \\
\hline 9 & F & $\mathrm{f}$ & lo & $f$ & $\mathrm{f}$ & $\mathrm{F}$ & F \\
\hline 10 & $\mathrm{f}$ & $\mathrm{f}$ & is & 6 & $\mathrm{f}$ & $\mathrm{F}$ & $\mathrm{f}$ \\
\hline 11 & $\mathrm{~F}$ & $\mathrm{f}$ & $\mathrm{F}$ & 6 & $\mathrm{~F}$ & F & F \\
\hline 12 & $\mathrm{f}$ & $\mathrm{f}$ & $\mathrm{F}$ & F & 8 & f & F \\
\hline$B$ & f & $\mathrm{f}$ & $\mathrm{F}$ & F & 6 & $\mathrm{f}$ & $\mathrm{F}$ \\
\hline 14 & $\mathrm{~F}$ & $f$ & $\mathrm{~F}$ & f & $\mathrm{f}$ & 8 & $\mathrm{f}$ \\
\hline 15 & $F$ & $\mathrm{~F}$ & $\mathrm{~F}$ & f & $\mathrm{F}$ & c & $\mathrm{F}$ \\
\hline 16 & $\mathrm{~F}$ & $\mathrm{~F}$ & $\mathrm{~F}$ & F & $\mathrm{F}$ & $\mathrm{F}$ & 1 \\
\hline 17 & $F$ & p & $F$ & $f$ & $\mathrm{f}$ & $\mathrm{f}$ & \\
\hline
\end{tabular}

Karakteristik Ekualiser. Flat berarti posisi potensiometer ditengah, Boost posisi potensiometer maksimal dan Cut posisi potensiometer di minimal.

Dari pengukuran yang dilakukan didapatkan hasil-hasil sebagai berikut : 


\begin{tabular}{|c|c|c|c|c|}
\hline Position & : & All Boost & & \\
\hline Vin & : & 100 & mult & \\
\hline No & Freq $[\mathrm{Hz}\}$ & $V_{0}(v)$ & vo/vi & $d B$ \\
\hline 1 & 10 & 268 & 2.68 & 8.562696 \\
\hline 2 & 20 & 280 & 2.8 & 8.943161 \\
\hline 3 & 30 & 300 & 3 & 9.542425 \\
\hline 4 & 50 & 400 & 4 & 12.0412 \\
\hline 5 & 100 & 700 & 7 & 16.90196 \\
\hline 6 & 200 & 760 & 7.6 & 17.61627 \\
\hline 7 & 300 & 808 & 8.08 & 18.14823 \\
\hline 8 & 500 & 552 & 5.52 & 14.83878 \\
\hline 9 & 1000 & 1220 & 12.2 & 21.7272 \\
\hline 10 & 2000 & 1000 & 10 & 20 \\
\hline 11 & 3000 & $10 \pi$ & 10.7 & 20.58768 \\
\hline 12 & 5000 & 1160 & 11.6 & 21.28916 \\
\hline 13 & 10000 & $B 32$ & 8.32 & 18.40247 \\
\hline 14 & 20000 & 656 & 6.56 & 16.33608 \\
\hline
\end{tabular}

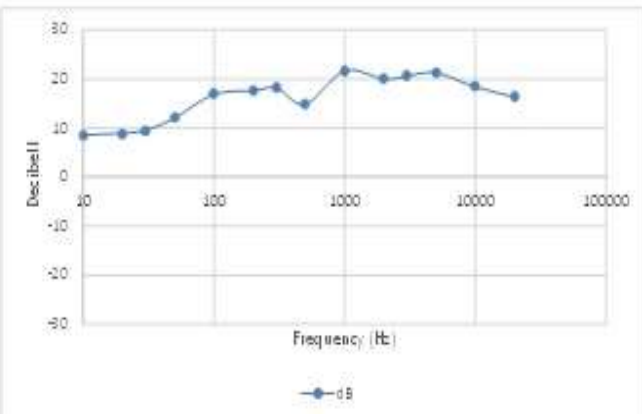

Gambar 6. Tabel dan grafik posisi semua potensiometer maksimal

\begin{tabular}{|c|c|c|c|c|}
\hline Position & : & All cut & & \\
\hline Vin & : & 100 & mvolt & \\
\hline No & Freq $(\mathrm{Hz})$ & vo (V) & wo/vi & $d B$ \\
\hline 1 & 10 & 12 & 0.12 & -18.4164 \\
\hline 2 & 20 & 15 & 0.16 & -15.9176 \\
\hline 3 & 30 & 16 & 0.16 & -15.9176 \\
\hline 4 & 50 & 16 & 0.16 & -15.9176 \\
\hline 5 & 100 & 20 & 0.2 & -13.9794 \\
\hline 6 & 200 & 40 & 0.4 & $-7,95 B B$ \\
\hline 7 & 300 & 36 & 0.36 & -8.87395 \\
\hline 8 & 500 & 68 & 0.68 & -3.34982 \\
\hline 9 & 1000 & 20 & 0.2 & -13.9794 \\
\hline 10 & 2000 & 28 & 0.28 & -11.0568 \\
\hline 11 & 3000 & 28 & 0.28 & -11.0568 \\
\hline 12 & 5000 & 24 & 0.24 & -12.3958 \\
\hline 13 & 10000 & 36 & 0.36 & -8.87395 \\
\hline 14 & 20000 & 45 & 0.45 & -6.74484 \\
\hline
\end{tabular}

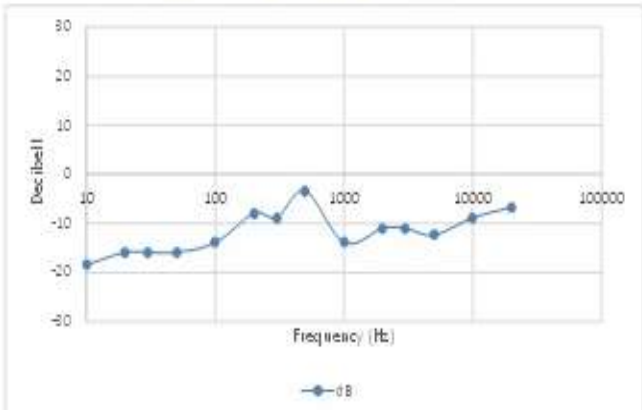

Gambar 7. Tabel dan grafik semua posisi potensiometer minimal

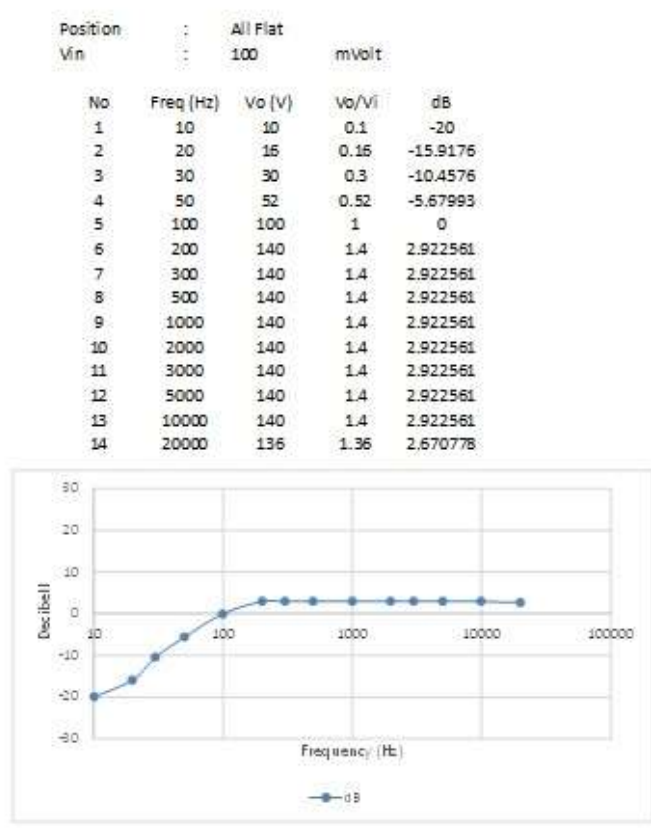

Gambar 8. Tabel dan grafik posisi semua potensiometer ditengah

\subsection{Implementasi Pengamatan}

Dengan adanya pengukuran output dari sebuah rangkaian ekualiser ini, diharapkan mahasiswa nantinya bisa memahami sebuah pengembangan rangkaian dari rangkaian-rangkaian filter yang telah dipelajari. Selain itu, metode pengukuran ini bisa dimasukkan dalam salah satu judul praktikum dasar sistem komunikasi dengan tema pengukuran karakteristik output ekualiser.

\subsection{Kesimpulan}

Dari pelaksanan penelitian ini kita bisa mengukur karakteristik output dari sebuah rangkaian ekualiser. Serta memahami sebuah pengembangan rangkaian dari rangkaian filter.

\subsection{Saran}

Dari hasil penelitian yang telah dilakukan ini, kedepan semoga bisa dikembangkan menjadi sebuah modul praktikum yang utuh dan lebih fleksibel untuk digunakan mahasiswa. 


\section{DAFTAR PUSTAKA}

1. Glen M. Ballaou (Ed.), 2015,

"Handbook for Sound Engineers,

Fifith Edition,", Focal Press.

2. Dr. Ir. Saludin Muis, M.Kom., 2015,

Teori Pengkodean Sinyal Audio,

Graha Ilmu.

3. Louis E. Frenzel, 2003, Principles of

Electronic Communication

Systems, McGraw.

4. Jonathan Feist, 2013, Audio

Mastering : Essential Practices, Hal

Leonard.

5. Bobby Owsinski, 2008, The Mastering Engineer's Handbook:

The Audio Mastering Handbook, Thomson Course Technology PTR.

6. John Linsley Hood, 2000, Audio

Electronics, Second Edition, Newnes.

7. Ian Hickman, 1991, Electronic Circuits, Systems and Standards: the Best of EDN, Newnes. 